\title{
Biologic Data of Macaca mulatta, Macaca fascicularis, and Saimiri sciureus Used for Research at the Fiocruz Primate Center
}

\section{Márcia Cristina Ribeiro Andrade/ ${ }^{+}$, Carlos Torres Ribeiro*, Virgílio Ferreira da Silva, Etelcia Moraes Molinaro, Miguel Ấngelo Brück Gonçalves, Marcos Antônio Pereira Marques, Pedro Hernan Cabello**, José Paulo Gagliardi Leite***}

\author{
Centro de Criação de Animais de Laboratório, Departamento de Primatologia-Fiocruz, Av. Brasil 4365, 21045-900 Rio de Janeiro, \\ RJ, Brasil *Faculdade de Medicina Veterinária, Universidade Federal Rural do Rio de Janeiro, Seropédica, RJ, Brasil \\ **Laboratório de Genética Humana, Departamento de Genética ***Laboratório de Virologia Comparada, Departamento de \\ Virologia, Instituto Oswaldo Cruz-Fiocruz, Rio de Janeiro, RJ, Brasil
}

Physiological parameters of laboratory animals used for biomedical research is crucial for following several experimental procedures. With the intent to establish baseline biologic parameters for non-human primates held in closed colonies, hematological and morphometric data of captive monkeys were determined. Data of clinically healthy rhesus macaques (Macaca mulatta), cynomolgus monkeys (Macaca fascicularis), and squirrel monkeys (Saimiri sciureus) were collected over a period of five years. Animals were separated according to sex and divided into five age groups. Hematological data were compared with those in the literature by Student's $t$ test. Discrepancies with significance levels of 0.1, 1 or 5\% were found in the hematological studies. Growth curves showed that the sexual dimorphism of rhesus monkeys appeared at an age of four years. In earlier ages, the differences between sexes could not be distinguished $(p<0.05)$. Sexual dimorphism in both squirrel monkeys and cynomolgus monkeys occurred at an age of about 32 months. Data presented in this paper could be useful for comparative studies using primates under similar conditions.

Key words: non-human primates - growth curve - hematological parameters - biologic data - biometry

The Primatology Department of the Center for Laboratory Animals Breeding of the Oswaldo Cruz Foundation (Fiocruz), Rio de Janeiro, Brazil, consists of approximately 300 rhesus macaques (Macaca mulatta), 90 cynomolgus monkeys (Macaca fascicularis), and 75 squirrel monkeys (Saimiri sciureus) for use in biomedical research.

The colony of rhesus monkeys was established in 1932 with 100 animals, initiated by Dr Carlos Chagas who proposed the use of rhesus for the development of a Yellow Fever vaccine. The animals were maintained semi-free on an island for about 50 years, where they were provided with a colony management program in terms of nutrition and reproduction with minimum conditions of sanitation (Coimbra-Filho \& Maia 1974). In 1980 the animals were moved to the campus at Fiocruz. The colony of cynomolgus monkeys was created in 1986, for neurovirulence tests of the Yellow Fever vaccine produced in fibroblast cultures. The colony of squirrel monkeys was established in 1987 with wild animals recovered from the Amazon region, with the intent to develop a vaccine against malaria. No new animals have been introduced to these colonies since their establishment.

The establishment of baseline biologic data for animals bred for scientific purposes is of basic importance for dealing with a series of practical situations in animal

${ }^{+}$Corresponding author. Fax: +55-21-2590.2434. E-mail: andrade@fiocruz.br

Received 26 February 2004

Accepted 2 August 2004 management, including diagnosis and treatment of sick animals, improvement of therapies and experimentation. Standardized hematological values are important complements to different scientific investigations (Melville et al. 1967), for example for toxicological evaluations of therapeutic agents (Nageswara \& Shipley 1970).

Similarly, morphologic parameters and the body growth curve must indicate growth disturbances and provide us with data for evaluating successful husbandry or allow us to make necessary adaptations.

Great discrepancies could be found in the literature with respect to hematological values (Melville et al. 1967). The different methods employed and studies lacking discrimination of sexes make a comparative analysis unfeasible (Manning et al. 1969, Ausman et al. 1976). In addition, one must always consider that the use of anesthetics (Martin et al. 1973, Matsumoto et al. 1980), number of studied animals, obtained standard deviation, and other important factors (Rollins et al. 1970, Patricia et al. 2000) may interfere with certain parameters (Altshuler et al. 1971, Buchl \& Howard 1997).

This paper aims to standardize hematological data and to establish some morphological parameters for three species of non-human primates held in closed colonies, through statistical analysis of data and comparison with other Primate Centers.

\section{MATERIALS AND METHODS}

Animals - The present study selected all clinically healthy non-human primates from the Fiocruz colony in order to analyze body weights, growth rates, sexual dimorphism, and hematological parameters. 
Animals were evaluated routinely by physical examination, blood profiles, and behavioral assessment. Since the present work aims to evaluate normal biologic values, animals with clinical diseases or apparent physiologic conditions were excluded from this study. All animals with abnormal bacteriological, hematological, or parasitological specimens at the time of collection were eliminated. Excluded animals represented $12.5 \%$ of the whole colony.

Data on animals selected for the study were obtained from health records over a five year period (1997 to 2001) since complete data were recorded in this period. Animals were divided into five age groups based on their stage of development and reproduction capacity: (1) baby monkeys (0- 6 months); (2) infants, post-weaned (7-18 months); (3) juveniles (19-31 months); (4) young monkeys, puberty (32-44 months), and (5) sexually-mature adults (45-192 months). Although squirrel monkeys are able to breed after 36 months (Taub et al. 1978, Rowe 1996), the preceding criteria has been established by Fiocruz for all species studied in its facilities.

The Old World primates (M. mulatta and M. fascicularis) are housed outdoors in big cages measuring 6 x 6 x $4 \mathrm{~m}$, while squirrel monkeys are held in smaller cages measuring $2 \times 3 \times 4 \mathrm{~m}$ in a building receiving natural light. The animals live in harem groups, with one male for eight to ten females, and are fed a commercially available pelleted primate diet supplemented with fresh fruits and vegetables which are rich source of vitamin $\mathrm{C}$ to avoid scurvy (Kaplan 1977, Demaray et al. 1978). Squirrel monkeys are unable to utilize vitamin D2 adequately (Kaplan 1977). However, in Fiocruz they are exposed to natural sun light, allowing them to utilize vitamin D3 without dietary supplements.

Medical management - Once a year, animals in the colony were examined, weighed, had blood drawn, were tuberculin tested, and treated with prophylatics against intestinal parasites. For this purpose, animals were anaesthetized with ketamine hydrochloride $(10 \mathrm{mg} / \mathrm{kg})$. The Old World monkeys were identified with tattoo marks in the chest region and the Neotropical primates at the medial left thigh. In the physical examination, the animals were weighed and body measurements were taken as follows: crown-rump length, taken from the external occipital protuberance to the base of the tail (first coccygeal vertebrate); thoracic perimeter, taken at the level of the axilla, and tail length, taken from the base to the end of the tail. These data were recorded in the medical records as morphometric parameters.

Blood samples from the Old World primates were collected via femoral venipuncture and placed in vacutainer ${ }^{\mathrm{TM}}$ tubes. From each animal, whole blood was collected for biochemical tests and serum banking. An additional volume of whole blood was collected for a complete hemogram, using ethylene diamine tetra-acetic acid (EDTA) as an anticoagulant. From the Neotropical primates, whole blood was collected for the same laboratory examinations via femoral venipuncture, using $5 \mathrm{ml}$ disposable syringes. Blood volume was collected by drawing an amount less than $10 \%$ of the animal pre-measure weight (Fortman et al. 2002).
All the studies were conducted according to guidelines set forth in the Guide for the Care and Use of Laboratory Animals.

Hematological studies - For the hematological studies, data were from adult animals grouped according to sex. The following analyses of blood components were performed using commercially available kits: cholesterol, urea, lipids, total protein and albumin, aminotransferases (AST and ALT) (CELM ${ }^{\mathrm{TM}}$ Cia Equipadora de Laboratórios Modernos, Barueri, SP, Brazil), and chlorides (LabTest ${ }^{\mathrm{TM}}$ Diagnostica S.A., Lagoa Santa, MG, Brazil). Total erythrocyte, leukocyte and hemoglobin counts were carried out with the cellular counter 530/550 (CELM ${ }^{\mathrm{TM}}$ Cia Equipadora de Laboratórios Modernos). Wright's coloration (Frankel 1970) was used for blood smears. Hematocrit values were performed according to standard procedures (Lima 2001). Commercial assays were conducted in accordance to the manufacturer's instructions.

Statistical analysis - The cytological and biochemical data were analyzed by Student's t test (Bussab \& Morethin 1993), with $p \leq 0.05$ being statistically significant. Diverging values were not considered according to previous recommendation (Stanley \& Cramer 1968, Buchl \& Howard 1997). Therefore, five rhesus monkeys, three squirrel monkeys and three cynomolgus monkeys, that were considered clinically health were excluded in this analysis, since they presented discrepancies in their hematological values, such as accentuated eosinophilia, leukocytosis and neutropenia, when compared with the rest of the analyzed groups.

The data obtained were compared with that found in the literature, using established methodologies similar to those used in the published works. Data were compared between animals housed under similar conditions. The morphometric parameters were examined by multivariate analysis of variance (MANOVA) for comparing the variations in the body measurements between sexes and different age groups. Analysis was performed using SPSS (Statistical Package for Social Science).

\section{RESULTS}

To more carefully analyze potential differences between animals in our colonies and data published from other colonies, data were collected and analyzed for animals according to age, reproductive maturity, and sex. In addition, a single blood sample was collected and a standard blood profile was recorded for each animal. The morphometric data are shown in Tables I to VI and the hematological parameters are shown in the Tables VII, VIII, and IX.

\section{DISCUSSION}

Research primates are in increasingly short supply. As the source of non-human primates extends into previously unutilized colonies, variations in normal physiologic parameters between animals of different colonies will become more important. In this study, we examined the morphometric and hematological parameters of our closed colonies of rhesus macaques, cynomolgus macaques, and squirrel monkeys. We retrospectively analyzed morphometric data for a five year period (1997-2001) from a large 
number of animals that likely have similar genetic background. A single blood sample was collected from all animals at the same time (during the breeding season). In addition, animals have all been managed with the same housing and feeding conditions. Finally, to maximize con- sistency within groups, animals were divided by age and sex. With these efforts to compare data from animals in homogenous groups, we were able to obtain representative data (Altshuler et al. 1971) and to establish baseline parameters for the colony (Rollins et al. 1970).

\section{TABLE I}

Morphometric data of rhesus monkeys (Macaca mulatta) males

\begin{tabular}{lcccc}
\hline Age group & Weight $(\mathrm{g})$ & Crown-rump $(\mathrm{cm})$ & Tail $(\mathrm{cm})$ & \multicolumn{2}{c}{ Thoracic perimeter $(\mathrm{cm})$} \\
\hline Babies & $1228 \pm 348.1$ & $23.52 \pm 2.57$ & $15.28 \pm 1.74$ & $19.19 \pm 2.33$ \\
$\mathrm{n}=45$ & $(600-1880)$ & $(18-29)$ & $(11-19)$ & $(15-29)$ \\
Infants & $2656.7 \pm 370.5$ & $31.41 \pm 3.58$ & $18.75 \pm 3.58$ & $26.62 \pm 4.08$ \\
$\mathrm{n}=24$ & $(1780-3240)$ & $(25-45)$ & $(13-24)$ & $(23-44)$ \\
Juveniles & $4135 \pm 300.4$ & $35.22 \pm 3.83$ & $21 \pm 1.58$ & $29.67 \pm 1.12$ \\
$\mathrm{n}=6$ & $(3800-4520)$ & $(31-39)$ & $23.12 \pm 1.89$ & $(29-32)$ \\
Youngs & $5455.7 \pm 625.75$ & $39.63 \pm 2.44$ & $(21-25)$ & $33.25 \pm 1.83$ \\
$\mathrm{n}=13$ & $(4440-6160)$ & $(35-43)$ & $25.31 \pm 4.15$ & $(32-36)$ \\
Adults & $10442.9 \pm 3275.7$ & $48.78 \pm 6.25$ & $(20-29)$ & $43.68 \pm 6.25$ \\
$\mathrm{n}=34$ & $(5700-16800)$ & $(41-56)$ & $(34-62)$ \\
\hline
\end{tabular}

Values are expressed as the mean \pm standard deviation; $n$ : number of studied animals in each age group; Babies: 0-6 months; Infants: 7-18 months; Juveniles: 19-31 months; Youngs: 32-44 months; Adults: 45-192 months

TABLE II

Morphometric data of rhesus monkeys (Macaca mulatta) females

\begin{tabular}{lcccc}
\hline Age group & Weight $(\mathrm{g})$ & Crown-rump $(\mathrm{cm})$ & Tail $(\mathrm{cm})$ & Thoracic perimeter $(\mathrm{cm})$ \\
\hline Babies & $1103.7 \pm 259.7$ & $23.07 \pm 2.26$ & $14.81 \pm 1.59$ & $18.74 \pm 1.36$ \\
$\mathrm{n}=43$ & $(610-1620)$ & $(18-27)$ & $(11-19)$ & $(15-21)$ \\
Infants & $2551.54 \pm 278.1$ & $30.96 \pm 2.01$ & $18.84 \pm 1.54$ & $25.26 \pm 1.19$ \\
$\mathrm{n}=26$ & $(2040-3100)$ & $(27-35)$ & $(16-22)$ & $(23-29)$ \\
Juveniles & $3489.2 \pm 303.6$ & $35 \pm 1.89$ & $21 \pm 1.58$ & $28 \pm 1.16$ \\
$\mathrm{n}=13$ & $(3080-4320)$ & $(32-38)$ & $(18-25)$ & $(26-31)$ \\
Youngs & $5215.6 \pm 684.2$ & $39 \pm 3.75$ & $(18-26)$ & $32 \pm 2.38$ \\
$\mathrm{n}=9$ & $(4560-6600)$ & $(29-42)$ & $23.08 \pm 3.14$ & $(30-37)$ \\
Adults & $8575.1 \pm 2026.7$ & $44.28 \pm 3.92$ & $(15-45)$ & $41.6 \pm 5.27$ \\
$\mathrm{n}=141$ & $(5000-15600)$ & $(22-52)$ & $(28-60)$ \\
\hline
\end{tabular}

Values are expressed as the mean \pm standard deviation; $n$ : number of studied animals in each age group; Babies: 0-6 months; Infants: 7-18 months; Juveniles: 19-31 months; Youngs: 32-44 months; Adults: 45-192 months

TABLE III

Morphometric data of cynomolgus monkeys (Macaca fascicularis) males

\begin{tabular}{lcccc}
\hline Age group & Weight $(\mathrm{g})$ & Crown-rump $(\mathrm{cm})$ & Tail $(\mathrm{cm})$ & Thoracic perimeter $(\mathrm{cm})$ \\
\hline Babies & $788.46 \pm 166.43$ & $21.23 \pm 1.92$ & $32.6 \pm 3.17$ & $16.8 \pm 1.86$ \\
$\mathrm{n}=13$ & $(560-1050)$ & $(18-24)$ & $(26-37)$ & $(14-20)$ \\
Infants & $1619.1 \pm 222.1$ & $28.42 \pm 1.68$ & $42.5 \pm 4.21$ & $21.41 \pm 1.24$ \\
$\mathrm{n}=12$ & $(1200-1960)$ & $(26-31)$ & $(32-50)$ & $(20-23)$ \\
Juveniles & $2362.7 \pm 313.95$ & $32.82 \pm 1.66$ & $(38.09 \pm 6.47$ & $24 \pm 2.32$ \\
$\mathrm{n}=11$ & $(1800-2920)$ & $(31-35)$ & $52.25 \pm 7.18$ & $(19-27)$ \\
Youngs & $3292.5 \pm 584.26$ & $35.5 \pm 3.06$ & $(32-59)$ & $27.17 \pm 1.80$ \\
$\mathrm{n}=12$ & $(2500-4300)$ & $(29-40)$ & $57.50 \pm 9.68$ & $(25-31)$ \\
Adults & $6418.2 \pm 1737.3$ & $43.50 \pm 5.35$ & $(35-69)$ & $35.5 \pm 3.78$ \\
$\mathrm{n}=22$ & $(3860-11350)$ & $(37-62)$ & $(30-43)$ \\
\hline
\end{tabular}

Values are expressed as the mean \pm standard deviation; $n$ : number of studied animals in each age group; Babies: 0-6 months; Infants:

7-18 months; Juveniles: 19-31 months; Youngs: 32-44 months; Adults: 45-192 months 
Comparison of normal hematologic parameters of animals in our colonies and data in the literature (Schultz 1961, Melville et al. 1967, Robinson \& Ziegler 1968, Stanley \& Cramer 1968, Altshuler et al. 1971, Ausman et al. 1976, Beland et al. 1979, Matsumoto et al. 1980, Suzuki 1981, Kakoma et al. 1985, 1987, Yoshida et al. 1989, Buchl \&
Howard 1997) revealed discrepancies with significance levels of $0.1,1$ or $5 \%$. The differences in the results may be accentuated by environmental factors and/or differences in the genetic make-up of our colony animals. Due to the fact that these have been closed colonies for several decades, the high incidence of inbreeding likely has

TABLE IV

Morphometric data of cynomolgus monkeys (Macaca fascicularis) females

\begin{tabular}{lcccc}
\hline Age group & Weigh $(\mathrm{g})$ & Crown-rump $(\mathrm{cm})$ & Tail $(\mathrm{cm})$ & Thoracic perimeter $(\mathrm{cm})$ \\
\hline Babies & $664.29 \pm 166.92$ & $20.29 \pm 1.50$ & $32 \pm 2.16$ & $(29-35)$ \\
$\mathrm{n}=7$ & $(420-860)$ & $(18-22)$ & $43.5 \pm 2.84$ & $(15-19)$ \\
Infants & $1492 \pm 209.01$ & $27.3 \pm 1.63$ & $(38-48)$ & $21.7 \pm 2.16$ \\
$\mathrm{n}=10$ & $(1200-1800)$ & $(24-29)$ & $48.2 \pm 2.14$ & $(19-27)$ \\
Juveniles & $2025 \pm 217.01$ & $32.8 \pm 2.57$ & $(45-51)$ & $23.1 \pm 1.10$ \\
$\mathrm{n}=10$ & $(1740-2400)$ & $(30-38)$ & $51.56 \pm 3.36$ & $(21-25)$ \\
Youngs & $2572.2 \pm 295.2$ & $34.78 \pm 1.64$ & $(48-59)$ & $25.33 \pm 1.41$ \\
$\mathrm{n}=9$ & $(2160-3000)$ & $(33-38)$ & $52.07 \pm 3.62$ & $(23-27)$ \\
Adults & $4490 \pm 1051.8$ & $39 \pm 2.14$ & $(46-58)$ & $32.21 \pm 2.86$ \\
$\mathrm{n}=14$ & $(3000-6100)$ & $(36-42)$ & $(27-37)$
\end{tabular}

Values are expressed as the mean \pm standard deviation; $n$ : number of studied animals in each age group; Babies: 0-6 months; Infants: 7-18 months; Juveniles: 19-31 months; Youngs: 32-44 months; Adults: 45-192 months

TABLE V

Morphometric data of squirrel monkeys (Saimiri sciureus) males

\begin{tabular}{|c|c|c|c|c|}
\hline Age group & Weight $(\mathrm{g})$ & Crown-rump $(\mathrm{cm})$ & Tail $(\mathrm{cm})$ & Thoracic perimeter $(\mathrm{cm})$ \\
\hline $\begin{array}{l}\text { Babies } \\
\mathrm{n}=13\end{array}$ & $\begin{array}{c}328 \pm 166 \\
(560-1050)\end{array}$ & $\begin{array}{c}20 \pm 3 \\
(15-27)\end{array}$ & $\begin{array}{c}32 \pm 3 \\
(28-37)\end{array}$ & $\begin{array}{c}12 \pm 1 \\
(11-13)\end{array}$ \\
\hline $\begin{array}{l}\text { Infants } \\
\mathrm{n}=17\end{array}$ & $\begin{array}{c}522 \pm 67 \\
(394-620)\end{array}$ & $\begin{array}{c}24 \pm 1 \\
(21-26)\end{array}$ & $\begin{array}{c}39 \pm 3 \\
(21-26)\end{array}$ & $\begin{array}{c}15 \pm 1 \\
(13-16)\end{array}$ \\
\hline $\begin{array}{l}\text { Juveniles } \\
\mathrm{n}=14\end{array}$ & $\begin{array}{c}671 \pm 58 \\
(550-750)\end{array}$ & $\begin{array}{c}26 \pm 2 \\
(22-30)\end{array}$ & $\begin{array}{c}40 \pm 2 \\
(38-44)\end{array}$ & $\begin{array}{c}16 \pm 1 \\
(14-17)\end{array}$ \\
\hline $\begin{array}{l}\text { Youngs } \\
\mathrm{n}=12\end{array}$ & $\begin{array}{c}745 \pm 88 \\
(580-900)\end{array}$ & $\begin{array}{c}27 \pm 1 \\
(25-29)\end{array}$ & $\begin{array}{c}40 \pm 2 \\
(37-43)\end{array}$ & $\begin{array}{c}17 \pm 1 \\
(15-19)\end{array}$ \\
\hline $\begin{array}{l}\text { Adults } \\
\mathrm{n}=15\end{array}$ & $\begin{array}{c}851 \pm 119 \\
(660-1100)\end{array}$ & $\begin{array}{c}27 \pm 2 \\
(21-30)\end{array}$ & $\begin{array}{c}40 \pm 2 \\
(35-42)\end{array}$ & $\begin{array}{c}17 \pm 1 \\
(16-19)\end{array}$ \\
\hline
\end{tabular}

Values are expressed as the mean \pm standard deviation; n: number of studied animals in each age group; Babies: 0-6 months; Infants: 7-18 months; Juveniles: 19-31 months; Youngs: 32-44 months; Adults: 45-192 months

TABLE VI

Morphometric data of squirrel monkeys (Saimiri sciureus) females

\begin{tabular}{|c|c|c|c|c|}
\hline Age group & Weight (g) & Crown-rump $(\mathrm{cm})$ & Tail $(\mathrm{cm})$ & Thoracic perimeter $(\mathrm{cm})$ \\
\hline $\begin{array}{l}\text { Babies } \\
n=13\end{array}$ & $\begin{array}{c}283 \pm 54 \\
(160-360)\end{array}$ & $\begin{array}{c}20 \pm 3 \\
(15-21)\end{array}$ & $\begin{array}{c}31 \pm 4 \\
(14-20)\end{array}$ & $\begin{array}{c}12 \pm 1 \\
(9-13)\end{array}$ \\
\hline $\begin{array}{l}\text { Infants } \\
\mathrm{n}=15\end{array}$ & $\begin{array}{c}498 \pm 61 \\
(327-570)\end{array}$ & $\begin{array}{c}24 \pm 1 \\
(22-25)\end{array}$ & $\begin{array}{c}39 \pm 2 \\
(37-45)\end{array}$ & $\begin{array}{c}14 \pm 1 \\
(14-15)\end{array}$ \\
\hline $\begin{array}{l}\text { Juveniles } \\
\mathrm{n}=11\end{array}$ & $\begin{array}{c}601 \pm 98 \\
(500-850)\end{array}$ & $\begin{array}{c}26 \pm 2 \\
(23-29)\end{array}$ & $\begin{array}{c}40 \pm 2 \\
(36-43)\end{array}$ & $\begin{array}{c}15 \pm 1 \\
(14-16)\end{array}$ \\
\hline $\begin{array}{l}\text { Youngs } \\
\mathrm{n}=15\end{array}$ & $\begin{array}{c}621 \pm 60 \\
(520-760)\end{array}$ & $\begin{array}{c}26 \pm 1 \\
(24-29)\end{array}$ & $\begin{array}{c}40 \pm 3 \\
(31-44)\end{array}$ & $\begin{array}{c}15 \pm 1 \\
(14-16)\end{array}$ \\
\hline $\begin{array}{l}\text { Adults } \\
\mathrm{n}=17\end{array}$ & $\begin{array}{c}664 \pm 71 \\
(560-800)\end{array}$ & $\begin{array}{c}26 \pm 2 \\
(22-28)\end{array}$ & $\begin{array}{c}41 \pm 2 \\
(37-45)\end{array}$ & $\begin{array}{c}16 \pm 1 \\
(14-17)\end{array}$ \\
\hline
\end{tabular}

Values are expressed as the mean \pm standard deviation; n: number of studied animals in each age group; Babies: 0-6 months; Infants: 7-18 months; Juveniles: 19-31 months; Youngs: 32-44 months; Adults: 45-192 months 


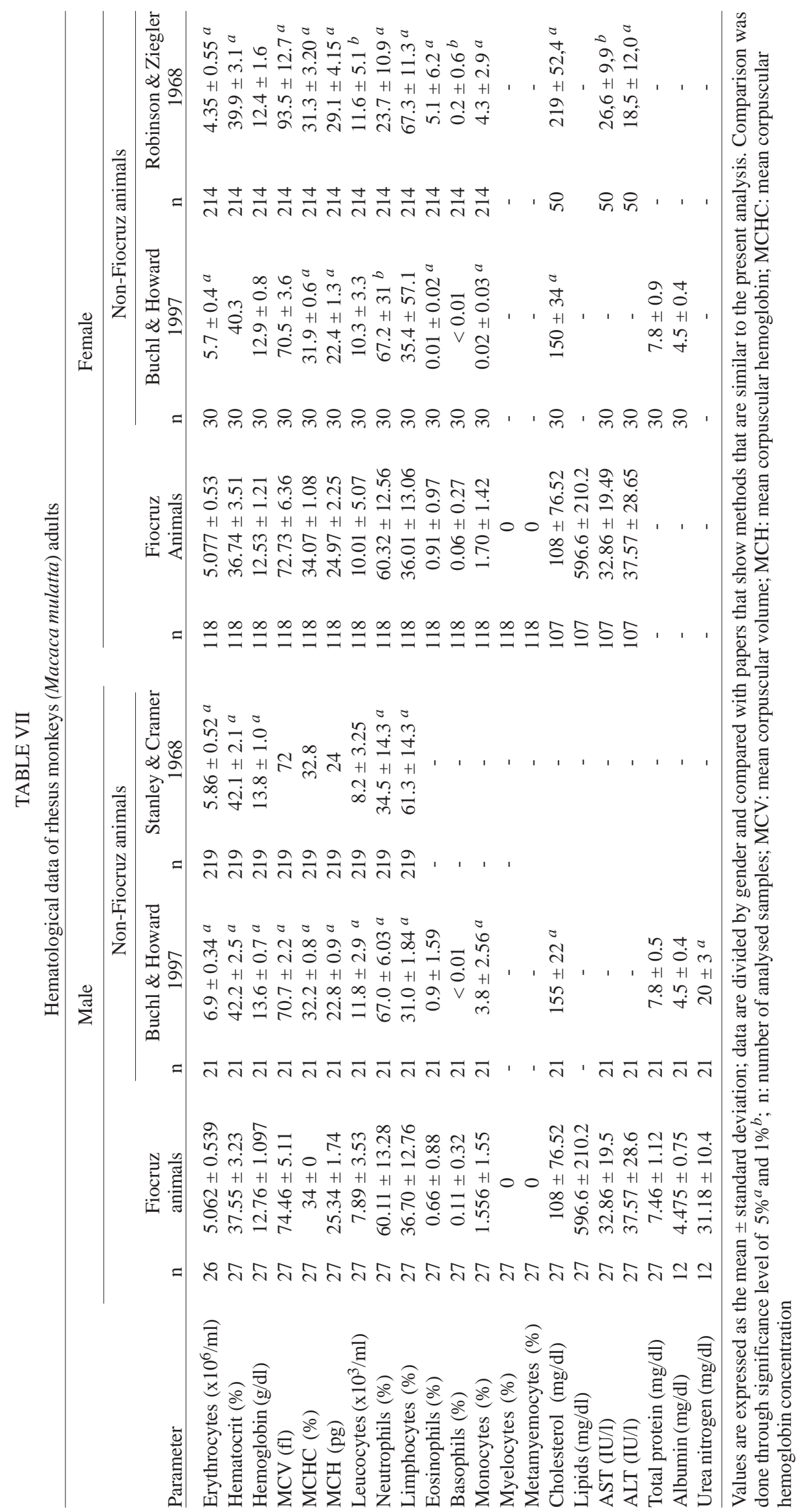




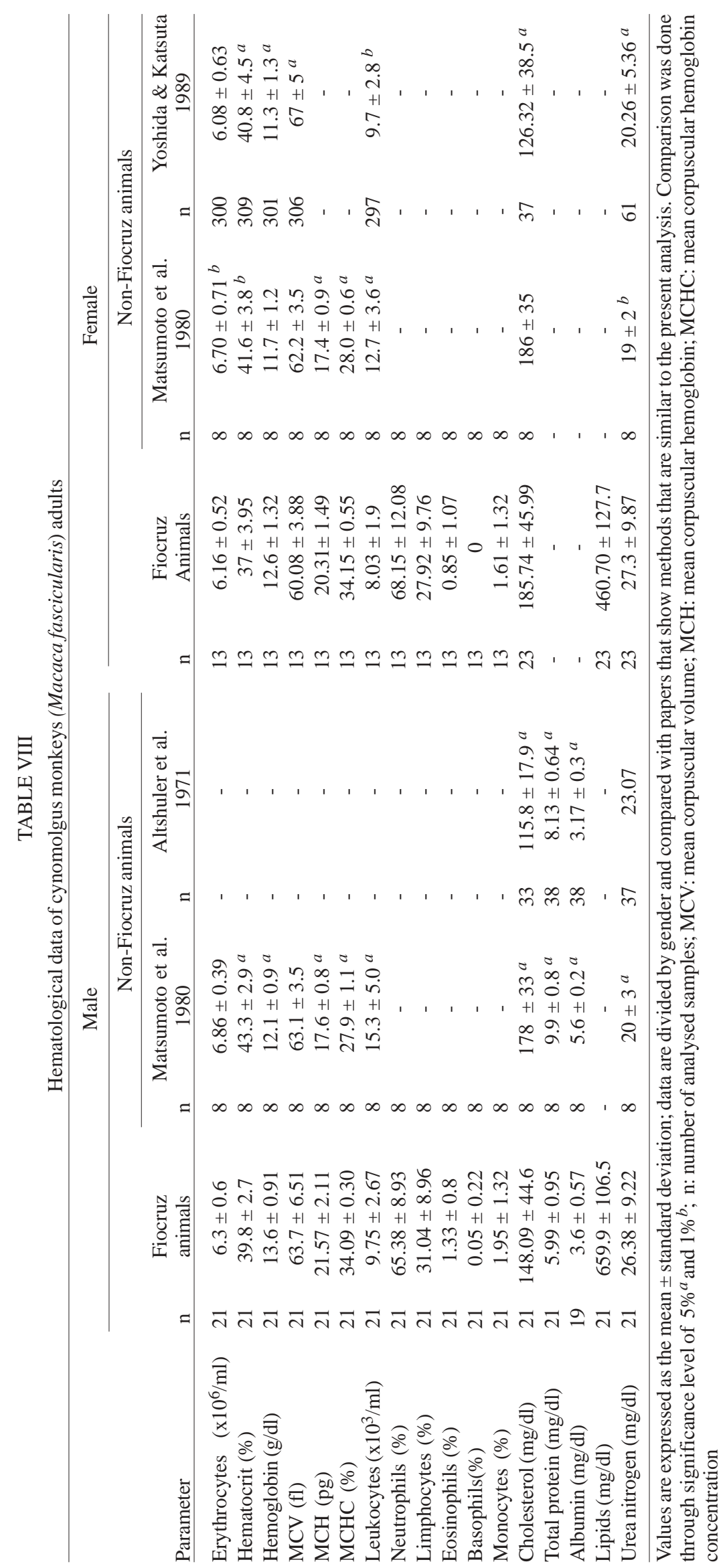




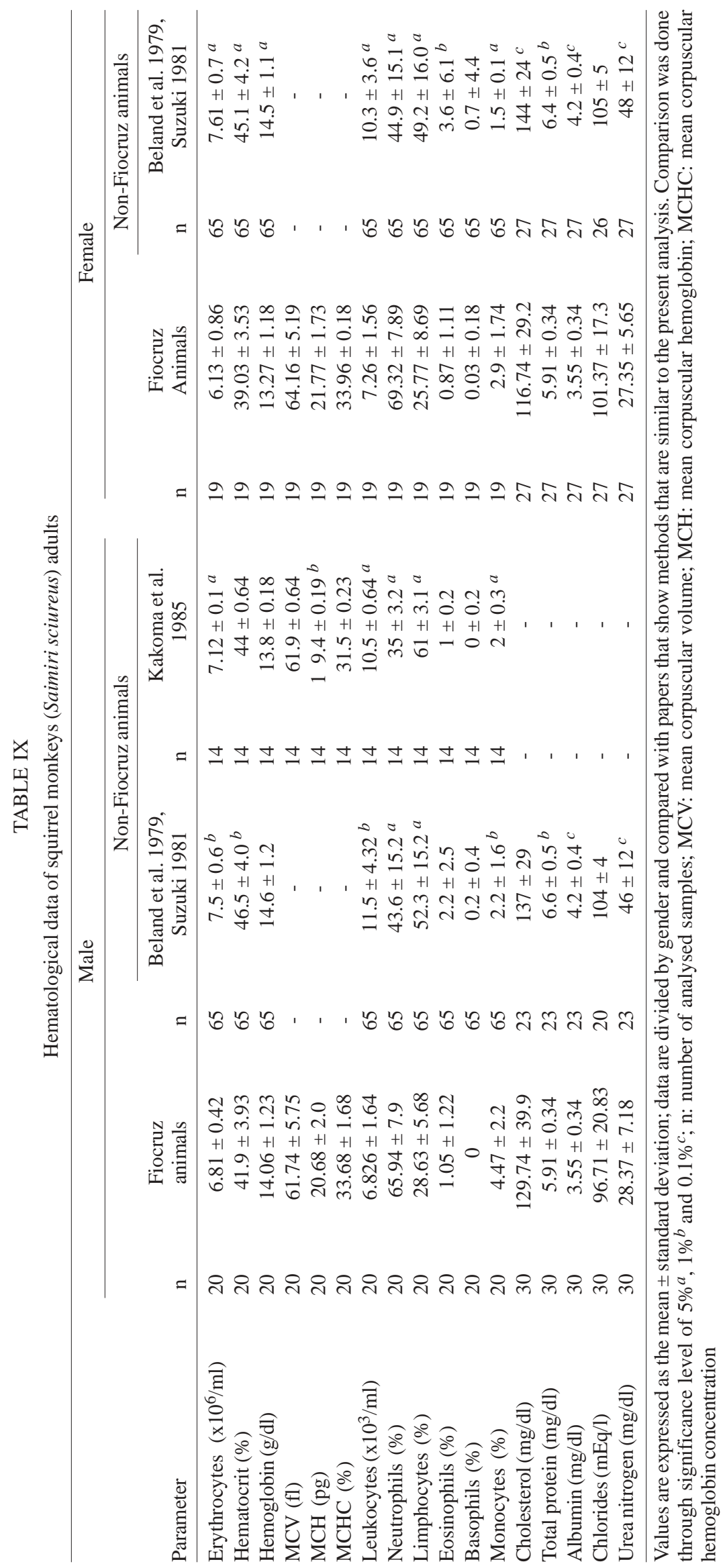


resulted in the emergence of genetic factors, which may have contributed to changes in the physical characteristics of the animals, including morphological and hematological parameters. Introduction of new animals could address this particular issue as well as improve the genetic conditions of this unique animal population.

The most significant difference between our colony and others was observed in the hematological data (Krise $\&$ Wald 1960). These differences may be due to several things including genetic differences, deficiency of vitamins (Kaplan 1977, Demaray et al. 1978), unrecognized disease (Melville et al. 1967), housing and stress conditions, and method of handling and blood collection. In addition, there was variation within our colony that suggests underlying disease, although the animals appear clinically healthy. Frequent episodes of alopecia, occurring during different periods of the year, affecting $25 \%$ of the rhesus monkey colony, may be an indication of stress, nutritional deficiencies, or disease. However, despite the alopecia, animals were considered healthy, since their behaviour and clinical conditions were normal when compared to the other animals of the colony. Another explanation for the discrepancies found could lie in the fact that the animals were held during many years in a closed reproduction system. This hypothesis, however, needs further, more extensive studies in the future.

Before undergoing venipuncture, the animals in the study were subjected to dissociative anesthesia with ketamine hydrochloride. Among the factors that provoke hematological changes and may have influenced the obtained results are the stress caused by physical restraint and anesthesia with ketamine hydrochloride (Ives \& Dack 1956, Loomis et al. 1980). This drug causes decrease in total proteins, hematocrit and leucocyte counts (mainly lymphocytes and neutrophils) (Loomis et al. 1980). On the other hand, the acute stress caused in the animals for not being used to handling, results in the so-called "alarm reaction" characterized by hemoconcentration (increase of hematocrit and total proteins), lymphocytosis and neutrophilia (Ives \& Dack 1956). This mechanism is related to the sympathetic response, displacing neutrophils from the capillary beds and releasing lymphocytes from the lymphatic system. Under anesthesia, however, circulating catecholamines are dispersed and the hemogram returns to normal levels. Compared with data in the literature, the analyzed animals presented accentuated lymphocytopenia, neutrophilia and discrete microcytic anemia.

With regards to squirrel monkeys, the urea nitrogen, albumin, and total protein levels differed from the literature found. The chloride values did not reach significant difference between the reported values in other colonies. However, while the cholesterol levels in males were similar, the females values were lower $(0.1 \%$ of significance level) (Beland et al. 1979). Reasons for such discrepancies need further investigation, including the possibility of a different nutritional strategy.

Regarding the morphometric data, body weights of the animals according to age and sex were similar to those described previously (Clarke \& O'Neil 1999). We verified that the weight of cynomolgus monkeys was similar to established findings, where the males weighed between
3.5 and $9 \mathrm{~kg}$ and the females between 3 and $6 \mathrm{~kg}$ (Altshuler et al. 1971). Growth curves (Figs 1, 2, 3) showed that the sexual dimorphism of rhesus monkeys appeared at four years of age. The differences between sexes could not be distinguished $(\alpha=0.05)$ at an earlier age. Sexual dimorphism found in the rhesus monkeys of this colony coincides with that in the literature (Schultz 1961). Sexual dimorphism in both squirrel monkeys and cynomolgus monkeys occurred at 32 months of age.

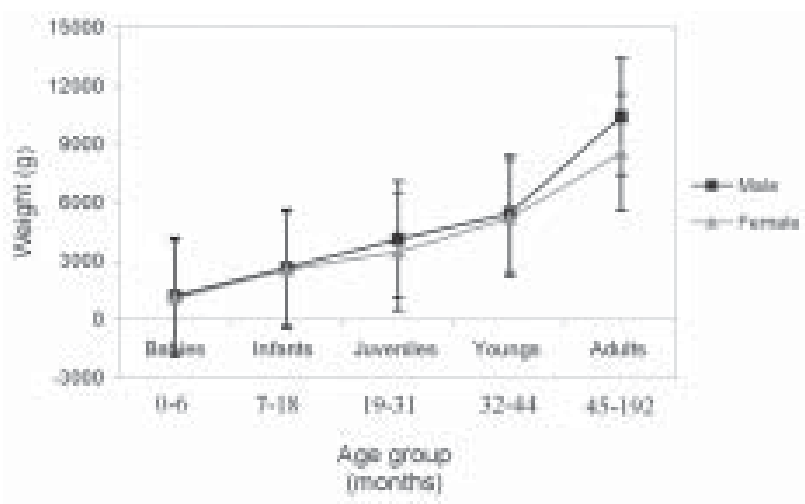

Fig 1: grown curve of rhesus monkeys (Macaca mulatta) in both sexes, divided by five age groups.

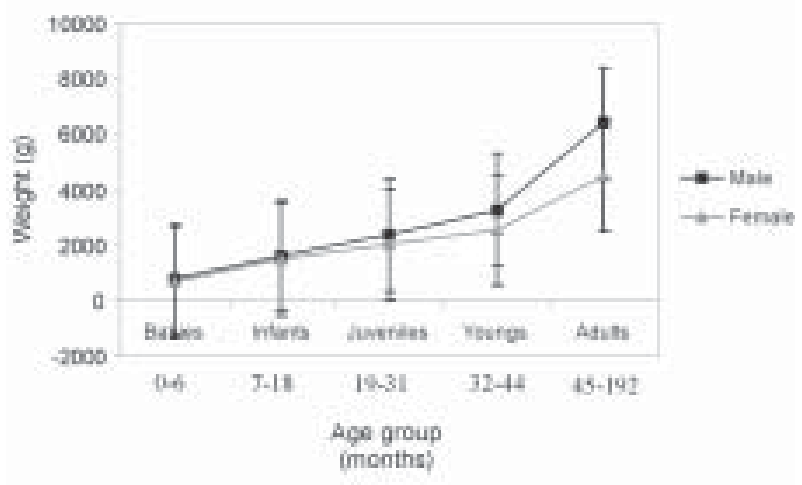

Fig 2: grown curve of cynomolgus monkeys (Macaca fascicularis) in both sexes, divided by five age groups.

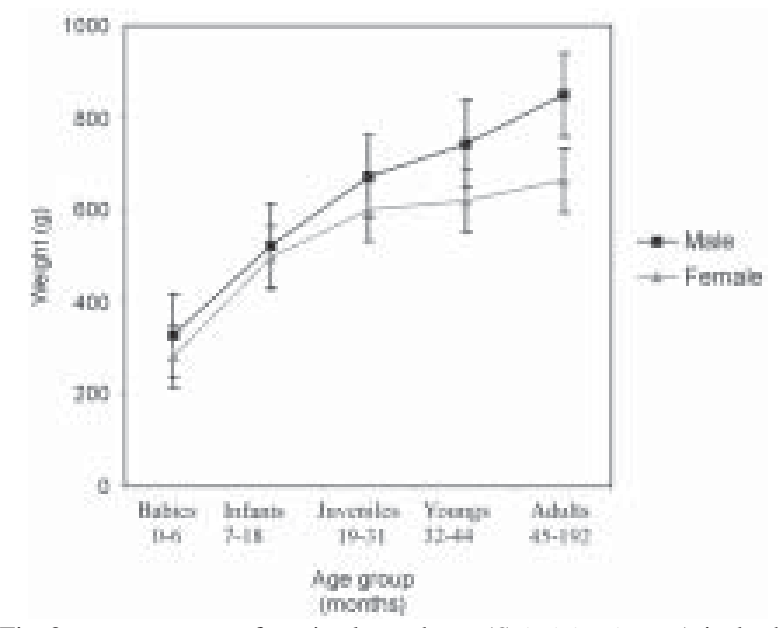

Fig 3: grown curve of squirrel monkeys (Saimiri sciureus) in both sexes, divided by five age groups. 
Because the squirrel monkey is smaller and more economical to maintain than larger non-human primates, it has become an extremely popular animal for research purposes. However, it is essential that optimal condition for their long-term maintenance and reproduction in captivity be identified and utilized (Rasmussen et al. 1980). Rasmussen et al. (1980) revealed that there was a highly significant relationship between birth weight and infant survival based on data collected from a largely indoor cage system. Studies in Fiocruz colony did not confirm this finding possibly due to a housing environment comparable with their natural setting.

In conclusion, the biological data and growth curves presented in this paper could be useful for comparative purposes in studies using primates under similar conditions.

\section{ACKNOWLEDGMENTS}

To the Department of Primatology staff from Fiocruz and Mr Cezar Caetano Sabia for their helpful contributions. To Dr Susan Westmoreland for reviewing the manuscript.

\section{REFERENCES}

Altshuler HL, Robert ES, Lowe RT 1971. Normal serum biochemical values of Macaca arctoides, M. fascicularis and M. radiata. Lab An Sci 21: 216-226.

Ausman LM, Gallina DL, Hayes KC, Hegsted DM 1976. Hematological development of the infant squirrel monkey (Saimiri sciureus). Folia Primatol 26: 292-300.

Beland MF, Sehgal PK, Peacock WC 1979. Baseline blood chemistry determinations in the squirrel monkey (Saimiri sciureus). Lab An Sci 29: 195-199.

Buchl SJ, Howard B 1997. Hematologic and serum biochemical and electrolyte values in clinically normal domestically bred rhesus monkeys (Macaca mulatta) according to age, sex, and gravidity. Lab An Sci 47: 528-533.

Bussab WO, Morethin PA 1993. Métodos quantitativos. In MR Spiegel, Estatística Básica, Atual, São Paulo, 266 pp.

Clarke MR, O'Neil JAS 1999. Morphometric comparison of chinese-origin and indian-derived rhesus monkeys (Macaca mulatta). Am J Primatol 47: 335-346.

Coimbra-Filho A, Maia AA 1974. Contribuição ao manejo racional da colônia de "rhesus" (Macaca mulatta) na ilha do Pinheiro, GB, Brasil - (Cercopithecidae-Primates). Brasil Florestal 5: 13-25.

Demaray SY, Altman NH, Ferrell TL 1978. Suspected ascorbic acid deficiency in a colony of squirrel monkeys (Saimiri sciureus). Lab An Sci 28: 457-460.

Fortman JD, Hewett TA, Bennet BT, 2002. The Laboratory Nonhuman Primates, CRC Press, Chicago, 288 pp.

Frankel S 1970. Gradwohl's Clinical Laboratory Methods and Diagnosis, 7th ed., Frankel, Reitman y Sonnenwirth, London, $123 \mathrm{pp}$.

Ives M, Dack GM 1956. "Alarm reaction" and normal blood pictures in Macaca mulatta. Lab \& Clin Med 47: 723-729.

Kakoma I, James MA, Jackson W, Bennett G, Ristic M 1985. Hematologic values of normal bolivian squirrel monkeys (Saimiri sciureus): a comparison between wild-caught and laboratory-bred male animals. Folia Primatol 44: 102-107.

Kakoma I, Bennet G, Carpunky P 1987. Correlative clinical biochemistry and hematological profiles of laboratory-bred bolivian squirrel monkeys (Saimiri sciureus). J Med Primatol 16: 273-276.

Kaplan JN 1977. Breeding and rearing squirrel monkeys (Saimiri sciureus) in captivity. Lab An Sci 27: 557-567.

Krise GM, Wald N 1960. Normal blood picture of the Macaca mulatta monkey. Ann NY Acad Sci 85: 803-810.

Lima AO 2001. Métodos de Laboratório Aplicados à Clínica Técnica e Interpretação, 6th ed., Guanabara Koogan, Rio de Janeiro, 664 pp.

Loomis MR, Henrickson RV, Anderson JH 1980. Effects of ketamine hydrochloride on the hemogram of rhesus monkeys (Macaca mulatta). Lab An Sci 30: 851-853.

Manning PJ, Lehner NDM, Feldner MA, Bullock BC 1969. Selected hematologic, serum chemical, and arterial blood gas characteristics of squirrel monkeys (Saimiri sciureus). Lab An Care 19: 831-837.

Martin DP, McGowan MJ, Loeb WF 1973. Age related changes of hematologic values in infant Macaca mulatta. Lab An Sci 23: 194-200.

Matsumoto K, Akagi H, Ochiai T, Hagino K, Sekita K, Kawasaki Y, Matin MA, Furuya T 1980. Comparative blood values of Macaca mulatta and Macaca fascicularis. Exp Anim 29: 335-340.

Melville GSJ, Whitcomb WH, Martinez RS 1967. Hematology of the Macaca mulatta monkey. Lab An Care 17: 180-198.

Nageswara RG, Shipley EG 1970. Data on selected clinical blood chemistry tests of adult female rhesus monkeys (Macaca mulatta). Lab An Care 20: 226-231.

Patricia RML, Zamudic CP, Arreola RJL 2000. Cuidado y utilización del mono cynomolgus (Macaca fascicularis) como modelo animal en la investigación biomédica. Animales de Experimentacion 5: 12-17.

Rasmussen KM, Ausman LM, Hayes KC 1980. Vital statistics from a laboratory breeding colony of squirrel monkeys (Saimiri sciureus). Lab An Sci 30: 99-106.

Robinson FR, Ziegler RF 1968. Clinical laboratory data derived from 102 Macaca mulatta. Lab An Care 18: 50-57.

Rollins JB, Hobbs CH, Spertzel RO, McConnell S 1970. Hematological studies of the rhesus monkey (Macaca mulatta). Lab An Care 20: 681-685.

Rowe N 1996. The Pictorial Guide to the Living Primates, Pogonias Press, Charlestown, 263 pp.

Schultz AH 1961. Growth and development. In CG Hartman, WL Straus (eds), Anatomy of the Rhesus Monkey, 2nd ed., Hafner Publishing, New York, 373 pp.

Stanley RE, Cramer MB 1968. Hematologic values of the monkey (Macaca mulatta). Am J Vet Res 29: 1041-1047.

Suzuki T 1981. Clinical laboratory studies on blood properties of the squirrel monkeys (Saimiri sciureus). J Med Sci Biol 34: 242-246.

Taub DM, Adams MR, Auerbach KG 1978. Reproductive performance in a breeding colony of brazilian squirrel monkeys (Saimiri sciureus). Lab An Sci 28: 562-566.

Yoshida T, Katsuta A, Cho F 1989. Reference values of hematological, serum biochemical and hormonal examinations in female cynomolgus monkeys (Macaca fascicularis) of feral origin. Exp Anim 38: 259-262. 
